END OF LIFE

\title{
Is the clock ticking for terminally ill patients in Israel? Preliminary comment on a proposal for a bill of rights for the terminally ill
}

\section{Y M Barilan}

See end of article for

authors' affiliations

J Med Ethics 2004;30:353-357. doi: 10.1136/jme.2002.000885

Correspondence to:

Y Michael Barilan,

MD, MA, Dept. Medicine

B, Meir Hospital, Kfar

Saba, Israel; bentovia@

shani.net

Received 28 October 2002

Revised version received

6 November 2002

Accepted for publication

24 January 2003

This paper presents and discusses a recent Israeli proposal to legislate on the rights of the dying patient. A gap exists between elitist biases of the committee proposing the law, and popular values and sentiments. The proposed law divides the dying patients into two groups: "those who wish to go on living" and "those who wish to die". The former will have a right to life prolonging extraordinary care. It is not clear who would foot the bill for this care. Also it is hard to see how this munificence could fail to discriminate against all other patients. Both the secular ethicists and the rabbis involved in drawing up the proposal accepted the assumption that it is good for some terminal patients to die. The rabbis objected, however, to direct and active interventions that shorten life. The solution arrived at was to install timers in the ventilators so as to allow them to expire automatically unless the patient wishes for their resetting.

$\mathrm{T}$ he National Steinberg Committee, which was established in 2000 by the Israeli minister of health to draft a law on the rights of terminally ill patients, recently issued its report. This is posted on the website of the Israeli ministry of health. ${ }^{1}$

The proposed law is meant to complement the 1996 Patient's Rights $\mathrm{Act}^{2}$ and the 1994 Bill of National Health Insurance.

Abraham Steinberg is a paediatric neurologist, an orthodox rabbi, and a professor of medical ethics in the faculty of medicine at the Hebrew University of Jerusalem.

The committee was divided into four subcommittees, medical, rabbinic, philosophical, and judicial. At the end plenary sessions were conducted among most of the 69 members, some of whom abstained from the discussions. A proposal for a law was submitted. It was accompanied by comments and reservations put forward by a minority of the committee's members. The Steinberg report deals extensively with issues such as living wills and proxy decision making; nutrition and hydration at the end of life; transparency in the processes of decision making; proper documentation, and exempting physicians from compliance with the requests of their patients on moral grounds. The proposal specifically prohibits any form of euthanasia, which is defined as "an act whose purpose or certain outcome is death".

Institutional judicial/ethical committees will have the legal authority when the caring team and the patient (or his/her proxies) disagree. A national judicial/ethical committee will have the final say whenever the institutional committee cannot arrive at a decision and whenever some party appeals against the decision of the local committee.

This article focuses on a few points, which may well be novel in the literature and worldwide practice of terminal care.

Israeli society is quite heterogeneous. Jews from all over the world and in different stages of assimilation make up $80 \%$ of the population. Many of them practise Orthodox Judaism, often within a strong communitarian context. Oriental Jews differ sociologically from Ashkenazi (European) Jews. The non-Jewish population is divided into
Muslim, Christian, Druze and a few other small groups. The influential social strata is highly Westernised and this was reflected in the membership of the Steinberg committee.

All committee members have advanced university or rabbinic education. Three of them were non-Jews, 14 were women. Although over $60 \%$ of the Jewish population in Israel is oriental, almost all members of the committee were Ashkenazi Jews. Only one out of the seven Orthodox rabbis was oriental. This is rather ironic since the ministry of health, which nominated the committee represents an ultraorthodox oriental religious party ("Shass"). Nor were Cabbalists (practitioners of mysticism), Chassidic rabbis and charismatic folk healers represented. On the other hand, the teachings of these rabbis are kept alive through the oral tradition. Their extensive influence is evident to clinicians in Israel. It is unclear to what extent the Steinberg committee tried to reckon with popular sentiment and practice. So far the transcriptions of the deliberations are not available to the public.

The author held lengthy and openhearted discussions with seven members of the committee. Yet, for the time being, responsible academic discussion of the Steinberg committee must be limited to the official report, which is not without ambiguities and obscurities, some of which will be pointed out below.

The Steinberg report divides the dying into two groups, those "who wish to go on living" and "those who wish to die $^{\prime \prime}$. State of the art life support and much more will be offered to the former; while efforts will be made to assist those who want to die within certain legal limits. Comprehensive palliative care will be offered to all.

A patient may nominate a proxy who will have the power to decide to which category the patient wanted to belong. According to the 1996 Patient's Rights Act a proxy has the power to consent, but not to refuse, medical care.

In the absence of a proxy, and when no evidence or testimony is available, the patient will be cared for as if he or she "wants to go on living", regardless of the clinical condition. The anonymous patient will be given full, ordinary life prolonging treatments even in the face of extreme agony. 
The only exception will be a patient who has less than two weeks to live, has more than one organ failure, and is suffering considerably.

The dominant trend among the non-orthodox members of the committee was that dying patients have a right to some form of euthanasia, so it was only Jewish religious law which was left to set limits on shortening the lives of terminal patients who wish to die.

It is of little doubt that the vast majority of the nonreligious members of the committee are well imbued with Western sensibilities and values. The rabbis were expert in Jewish law, which also puts strong emphasis on personal autonomy.

Indeed, the report fully acknowledges the primary value of autonomy and the absolute right a patient has to refuse medical care. Nevertheless, the draft states that the caring team has a duty to "exert every effort to persuade the patient to accept hydration, nutrition, oxygen, and other forms of palliative care". The discussants could not reach agreement about whether a dying patient has a right to refuse nutrition and palliation.

According to the 1996 Patient's Rights Act a juridical/ ethical committee has the legal power to override the explicit wishes of patients in certain sorts of life saving situations.

Nevertheless, according to Jewish tradition, the extreme vulnerability of the dying patient actually confers upon him or her special immunity from coercion and from what the patient might experience as disrespect to his or her last wishes. Mental competence is not a prerequisite for experiencing emotional pain. Rabbinic law operates on the assumption that suffering and frustration shorten the lives of the dying. This medical presupposition, which to the best of my knowledge has no parallel in ancient medicine, actually neutralises the conflict between the value of human life and the value of autonomy, as it renders it impossible to benefit the dying patient, or to prolong her life, by acting forcibly against her will. Indeed, the Steinberg report expresses a consensus that paternalistic coercion of the dying patient to eat or receive other forms of basic care is impractical, degrading to human dignity, and possibly even medically harmful.

Persuasion has received skimpy attention in the bioethical literature. ${ }^{3}$ It is a novel notion that the caring team as a whole has a moral duty to persuade the patient. This is an almost inevitable outcome of a situation in which paternalism has become a self defeating act. On the other hand, it is possible that the members of the committee would have agreed there was a duty to persuade every patient, had not the charter of the committee been limited to the dying.

Many traditional Jews and observant Muslims seek guidance from mystics and charismatic sages who often preach the value of human life as such. A son of one of my patients told me once "every breath drawn by a Jew exerts positive influence in the divine court in Heaven". Little has been written about such theurgic beliefs and their prevalence among different communities in Israel. My own personal experience as a practitioner on an internal medicine ward is that many of my Oriental and Chassidic patients gravitate toward some form of mystical vitalism. These groups were underrepresented on the Steinberg committee, and experts in religious law, let alone, the secular academic elite, often look down on what they see as their religiosity. In matters of life and death, it is quite unclear whether it is the rabbis, who are expert in religious law and theology, or the charismatic mystics and leaders of folk religion, who exercise more influence on the majority of religious and traditional Jews. The rabbis-for example, encourage donations from nonheartbeating donors (they are divided on the issue of brain death) but most requests are turned down, often with explicit concerns about spiritual harm and tampering with reincarnation or resurrection.

Pleadings "to do everything" are not uncommon from Western oriented Jews. Often it is very difficult to tell whether such requests stem from vitalism or from hopes for recovery. Such hopes often rely for support in blessings or amulets, or they are based on desperate wishful thinking.

The 1996 Patient's Rights Act prohibits the discussing of a patient's condition with his or her family without the patient's prior consent. The family actually has no standing in the 1996 law, which blankly refers to sharing information with a "third party".

In actuality, most doctors I know freely converse with the immediate and even broader family.

In this regard, the Steinberg report comes closer to reality than the 1996 law in that it recognises the role of "close friend and kin" in determining the values and wishes of the now incompetent patient. The caring team must respect the unanimous testimony of all family members and close friends, even when this amounts to only a single relevant person. Where such testimonies are not unanimous they are only to be weighed alongside other factors. A testimony by an intimate friend will be considered weightier than that given by a mere blood relation. The "personal physician" must be consulted as well.

The Steinberg report, however, does not specify what kind of information may be revealed to "close friends and kin". This apparent conflict between two aspects of the value of autonomy, namely respecting the wishes and values of a person on the one hand, and his medical confidentiality on the other, deserves more comprehensive attention than the report gives it.

The proposed law recognises a duty to provide the family, as well as the patient, with supportive care.

The Steinberg committee expressed concerns about perceived links between decision making in terminal care and the allocation of scarce resources in health care. The drafted law, therefore, tries to present the rights of the dying patient in a balanced way. Not only has she the right to refuse care, but also to insist on receiving life prolonging care even "beyond what is offered by the caring team", unless the therapy requested is deemed "harmful" or "not likely to prolong life".

The report deems the injudicial use of broad spectrum antibiotics in ways that are expected to produce resistant strains than to benefit the patient, a paradigmatic case that justifies denial of "harmful extraordinary therapy".

A minority of committee members objected, arguing that a patient has a right to receive such therapy.

This suggestion seems paradoxical. The terminal patient would most likely seek extraordinary palliation, not prolongation of life. The 1994 National Health Insurance Act does not, however, cover hospice care, nor is it mentioned in the Steinberg report.

Many patients and family members seek permission to invite "alternative" practitioners or licensed physicians with high tech experimental therapies to the bedside of critical and hopeless patients. I know of no ward in Israel that refuses such requests as long as the guests, some of whom can perhaps be described as bizarre, do not disturb hospital routine and safety. Official recognition of a "right" to treatment beyond the standards of medical practice might, however, open the door to "alternative" practitioners and questionable practices.

I think most terminal patients do not fit well into the radically dichotomous division between those "who want to live" and those "who want to die". The report mistakenly identifies a desire to go on living with a desire to fight for one's life by all means possible, or to exercise full control over 
one's death and dying. Acceptance of death and a wish to go on living are not exclusive attitudes. They complement each other gracefully. Dying patients usually refrain from struggle either to survive or to die. They merely seek support, palliation, and meaningful life until death arrives. This is also reflected in the World Health Organisation's (WHO) statement: "palliative care neither hastens nor postpones death". ${ }^{4}$

Contemporary rabbinic Judaism does not issue policy statements, guidelines or codes of practice similar to that of Maimonides. Jewish religious law is based on extrapolations from casuistic responsa given by rabbis to specific questions. Individual counselling by the rabbis is known to be lenient and accommodating to the autonomy of the person. Thus, spiritual care in Judaism is much more than mere support. Many dying patients need access to a rabbi in order to make informed decisions. Spiritual care is not provided by the Israeli health care services, nor is it mentioned in the Steinberg report.

In spite of the bill being cast in the language of rights, the draft does not point to the party responsible for responding to the exceptional needs of the dying patient. Apparently, the committee assumes that should the draft become legislation, it will fall within the ambit of the 1994 National Health Insurance law. According to this law a special committee decides the extent of the medical services which are covered by national health insurance. The use of legislation in order to add new items to the medical services to be offered by the national health service will bypass this special committee and the fair process of allocating resources among all the needy. The Steinberg report explicitly rejects the application of the concept of "futility" to the dying patient. Even given a hypothetical setting where there were no financial limitations, it would seem rather strange to offer every available medical intervention to patients who wanted to cling to life. As the case of "extraordinary therapies" shows, rationing is not the only reason for setting limits on medical activity; take-for example, the use of "alternative" practitioners mentioned above. Will these be hired in cases where funding is not an issue?

Bioethics has grown accustomed to the notion that "extraordinary" care is withheld from the dying. If, however, "extraordinariness" is measured by the intensity of technology and economical price rather than by the curative intent, then we have to face the fact that many patients need extraordinary palliative care in order to make their life bearable.

Palliative care has no "hard endpoints" such as mortality rate or any other measurable objective: it simply aims at the subjective feeling of palliation. This situation makes it very difficult to distinguish between the provision of tolerable comfort and medical palliation, between the fulfilment of desires and the provision of medical solutions. Whenever a patient has a right to opt for death, whether by means of active euthanasia or merely by becoming a "patient who does not want to live", the caring team finds itself in a quandary. To what lengths should society in general and medicine in particular go in order to satisfy the wishes of the dying and to preserve their motivation to stay alive?

In another paper I argue that it is unethical to withhold mind altering drugs from terminal patients while allowing them to opt for "no treatment" or even assisted suicide. Some patients might find satisfactory palliation only with the help of cheap drugs such as marijuana and LSD. ${ }^{5}$ Because of the taboo on drugs in Western and Muslim societies, these drugs are only culturally "extraordinary", despite the fact that they are both simple and cheap to use in the context of palliation.
Some patients who do not wish to live, might possibly change their minds if provided with supportive care beyond their means such as a personal nurse or, machines which are easy to use-for example, patient controlled analgesia (PCA) - and if sophisticated and unconventional care were available at home rather than in an institution.

The inconsistencies among the National Health Insurance Bill, The Patient's Rights Act and the Steinberg report epitomise genuine dilemmas of the modern welfare state, and its need to balance moral rights, allocation of resources, and sincere attempts to meet the challenges of maintaining human dignity in its most vulnerable state.

It is no secret that the world of bioethics in general is divided between those who approve of actions that help terminal patients to die and those who deem any action whose intended outcome is the death of a patient as wrongful killing and a violation of the sanctity of human life. Indeed, the Steinberg report confesses to profound disagreements in these matters. Broader, almost universal, consensus exists regarding the right to forgo medical interventions. Most of the doctors and secular ethicists on the committee were of the opinion that it is sometimes permissible to act with the explicit intention to cause death. To this, the orthodox rabbis objected. The rabbis did not object to the notion that death is good for some terminal patients. They were bound by the religious law, which sometimes expects the believer to act against her own good. The faithful Jew is the servant of God, not of his own physical or spiritual fulfilment. The religious law distinguishes between acts of commission and acts of omission. It is neither the context nor the consequences that matter in this regard but the ways in which human agency is involved. According to Jewish law, homicide is a double offence. It is an insult to the victim and a sin in the eyes of God. This human/divine aspect is discussed by McCloskey. ${ }^{6}$ As far as the victim is concerned, failure to act and save a drowning person-for example is as bad, or almost as bad, as active killing. Yet, since death is not considered harmful to the terminal patient who wants to die, euthanasia is possibly wrong only within the religious dimension, not the interpersonal one. According to Jewish law, in the eyes of God, a person is responsible for an action he commits, but not for things that merely happen. Possibly, the reason for this is that inaction leaves responsibility in the hands of God, which humans might usurp by active intervention. The world is God's realm and humans are expected to interfere only when commanded to by God or within the bounds of action allotted by Him.?

The rabbis sympathised with the dying who wish to terminate their agony as fast as possible. Most rabbinic authorities rule that it is permissible to pray to God to take the life of a suffering patient. Nevertheless, the rabbis were also adamant in their refusal to allow any active intervention that hastens death. I discuss the Jewish theological aspects of end of life issues and the Steinberg report in a paper published in the Kennedy Institute of Ethics Journal. ${ }^{8}$

The emphasis on physical action actually ignores the distinction between withholding treatment ( $a b$ initio) and withdrawing an ongoing treatment. The only question asked is whether an active physical action is taken with the intent of shortening life.

As it was apparent that the source of the controversy was actually a juridical hurdle in Jewish religious law, the committee did not despair of finding a solution with which they could all agree. It first set out to make a distinction between "discrete" and "continuous" modalities of treatment. Discrete treatments, such as blood transfusion or dialysis, begin and end at specific moments. Continuous care, such as mechanical ventilation, goes on and on without interruption. The committee agreed that cycles of discrete 
treatments could be stopped since every cycle may be conceived as an initiation of a new treatment. Refraining from additional cycles does not constitute an active act that hastens the end of life. The problem of the patient on continuous therapy is, however, more pressing. Obviously, a patient may choose not to be placed on a ventilator in the first place, but the patient who is already receiving mechanical ventilation may find himself trapped by medical technology, unable to do much about it. Death from suffocation is quite distressing; and even if the patient or his proxy can technically switch off the ventilator, they are still facing the moral and psychological problem of active killing and the medical challenge of adequate palliation during the process of dying. (The distinction between active action and abstaining from action has a philosophical and psychological basis as well. See the paper by Kamm. ${ }^{9}$ )

The Steinberg report proposes to install a timer in the ventilator so as to transform continuous care into a form of repetitively discrete care. The timer will automatically switch off the respirator every day or so unless someone intentionally turns it on once again. The resetting of the clock will be thus incorporated into routine care unless the patient explicitly asks that this not be done. This arrangement will also allow for some reflection since, as long as the clock is ticking, the patient can change her mind and request that the clock be turned off. Shortly before the clock is about to stop, the caring team would institute supportive care as if the patient had never been on a ventilator and had simply chosen not to be ventilated in the first place.

Dr Meir, the director general of a religious hospital in Jerusalem, initially proposed the clock machines in 1978 in a letter to Rabbi Waldenberg. Not only did the rabbi enthusiastically endorse the idea, but also ruled that the clocks must not be reset if the patient is incapable of rudimentary spontaneous respiration. ${ }^{10-16} \dagger$

Another prominent ultraorthodox rabbi ruled in 1990 that clock machines may be similarly used in order to disconnect a hopeless patient from a respirator for the sake of a new patient who might be saved. ${ }^{17}$

The demerits of the clock ventilator concept seem to be rather numerous. It is not clear which patients will be placed on this device and which will not. The possible ramifications of being on a "clock machine" as opposed to a regular one have not been discussed, nor have they been anywhere tested. The proposed law is not clear regarding the possible right of a patient to choose whether to be placed on a clock machine in the first place. I am particularly worried about the possible psychological impact on patient and family of being designated to therapy which is engineered with the explicit intent of allowing for passive euthanasia.

Patients might feel the "ticking of the clock" intolerable and find the burden of Sisyphean thinking about whether to go on living too heavy to bear. Some might fear that the standard of their care is in jeopardy once they are stigmatised as "clock patients". The committee did not have a mandate to decide on the cases of non-terminal but profoundly disabled people who depend on artificial ventilation. These patients might feel discriminated against should their request for a clock machine be denied.

${ }^{\dagger}$ The Steinberg report fails to credit Dr Meir and Rabbi Sternbuch for the idea. I do not know why the clock ventilators never materialised. Contemporary legislation had better take lessons from the past. As a matter of fact, according to Waldenberg's responsum there is no duty to implement artificial life support, and it is also allowed to disconnect them. He actually suggests that there might be a religious duty (mitzvah) to disconnect artificial life support when the patient is suffering. Many discussants of Jewish bioethics who elaborate on other responsa by Waldenberg, ignore this responsum. See-for example: Zohar, Rosner, Sherwin, Dorff, Pellegrino and A I Faden, and Resnicoff. ${ }^{11-16}$
Professor Steinberg has told me that the intent was to transform all respirators in Israel into clock respirators. I do not understand how this can respect the autonomy and safety of the vast majority of patients who need mechanical ventilation and who are not likely to be interested in stopping it at all. Rabbi professor Steinberg was also unaware of the fact that "clock ventilators" already existed. These are the small ventilators used when transferring patients from one place in the hospital to another. The energy is derived from the pressure in the oxygen tank. If allowed to peter out, the ventilator will stop working.

If the draft is enacted into law, many patients and medical professionals will have to deal with an experimental device that has no technical, legal or moral precedent. Moreover, monitoring the clocks in order to avoid the accidental termination of life support might be extremely risky. Human errors are already responsible for too many medical disasters; and the clock ventilator seems to be inviting even more slipups.

The clock ventilators appear as a sophisticated sleight of hand which avoids any genuine confrontation with the underlining moral problems encountered at the deathbed, such as the conflict between autonomy and the value of life, the good of the patient, and so on. Those who are attentive to "slippery slope" arguments might fear the spillover of technological/legal acrobatics into other domains of bioethics which will mean the moral issues at the heart of the problem can safely be avoided.

Acquaintance with the Jewish/Israeli setting might help readers to understand the formation of the "clock machines" concept. Jewish religious law operates in the spirit of positive law rather than in that of natural law. The secular law system in Israel is an inheritance of the common law enacted during the British mandate in Palestine (1919-1948), but the founding fathers of the Israeli legal system brought the German legal tradition with them, primarily that of the Weimar Republic. The combination of traditional law and modern positive law can put a strong emphasis on the "logic of antecedents" at the expense of the "logic of consequences". ${ }^{18}$

Israeli medicine is rather young and has not known major crises of trust. Concerns about inherent moral weaknesses within the biomedical establishment are almost absent from rabbinic discourse. Most Orthodox rabbis, never having received an academic education, rarely question professional judgment in the way cultural critics and deconstructivists do. An almost naïve embrace of technology may well account for the development of the clock ventilators solution. Similar apparatuses are employed in solving difficulties in Jewish Religious law (halakha) - for example, since direct and active operation of electrical appliances is prohibited on the Sabbath, observant Jews are used to semiautomatic devices whose action is suspended and resumed by a clock. These automata enable the user to turn on a switch or manipulate a valve during the breaks, thus turning a direct operation into an indirect one, or turning an event of acting into an event of abstaining from action. When the clock shifts the status of the device from idle to active, the new manipulation takes effect. Orthodox Judaism does not consider such solutions as a form of trickery, but as an integral part of devout religious life. The import of halakhaic solutions into the realm of medical care is not an innocuous move. The possible mishandling of terminal care bears directly on human affairs, whereas the possible violations of the laws concerning the Sabbath do not.

From historical and political points of view, the achievement of a consensus between secular/utilitarian ethicists and orthodox rabbis should not be underestimated. The former considered the clock machines superfluous and morally 
confounding; but they found no moral fault in their use, because the patient's autonomy was fully preserved. Additionally, in my view, the transformation of continuous care into cyclical care is an important stepping stone to the demedicalisation of many patients who feel that they are prisoners of medicine and its machines. Forcing the decision makers to reassess the goals and means of therapy over and over again could enhance quality of care.

The debate over the clock machines fits well into a constructivist analysis of technology. Machines are not value free. Their design reflects an underlying social struggle about power and about the ultimate aims of the technology in question, see-for example Questioning Technology by A Feenberg. ${ }^{19}$ Many authors consider that the very use of technology in palliative care is more likely to interfere with than to lead to a good death. For a recent discussion see $A$ Good Death: on the Value of Death and Dying by L Sandman. ${ }^{20}$ Recasting the design of machines and the concept behind their use may, however, empower patients and promote "good deaths".

Finally, I would dare suggest a somewhat different approach to the problem of terminating a continuous life support system that is no longer desired. My proposal seeks to learn from the concept of clock ventilators while avoiding at least some of their disadvantages.

I do not suppose the following suggestion will provide a satisfying solution for every terminal patient. My intent is merely to show how the concept of the clock machines might inspire a re-evaluation of the uses of medical technology at the death and also in other medical contexts.

I propose that a special switch be added to the ventilators (and possibly to pacemakers and intracardiac defibrillators) the control of which to be strictly in the hands of the patient or his proxy. Turning the switch on will start a timer that will disconnect the ventilator within a day or so. The caring team will be alerted whenever the switch is turned on so as to allow time for verification and for the timely institution of sedation and other forms of support. The ventilator will thus be transformed from an automaton into a device in the service of the patient, similar to patient controlled analgesia. The use of the latter at the full discretion of the patient and without a ceiling for dosing can also help in the restoration of autonomy and in the demedicalisation of the dying process.

Technology cannot serve as a fig leaf to hide moral problems, but it can help patients to act autonomously and responsibly. Contemporary engineering makes it possible for the very frail to control their environment by means of sophisticated modes of communication and action that make use of rudimentary muscle function or even the blink of an eye. This kind of technology empowers virtually every mentally competent patient not only to have a wish but also to act upon it.

Even if the clock ventilators fail to materialise as a practical implement and a legal solution, the concept has much to offer terminal care and the practice of medicine in general. Perhaps there is no role in our society for permanent and irreversible medical interventions whatsoever.

In a recent comment on the Dutch euthanasia act, Jos Welie asked: "Why the physician?"21 Indeed, modifying medical devices allows patients to make a choice and to act in matters that actually reach beyond the scope of medicine. The doctors know how to use medical technology, but decisions over the ultimate goals of the patient/medicine interaction belong to the patient.

\section{REFERENCES}

1 http://www.health.gov.il/pages/stainberg.htm (accessed 14 Apr 2004). 2 http://www.health.gov.il/pages/files/HOKZHOLE.pdf (accessed $14 \mathrm{Apr}$ 2004).

3 Barilan YM, Weintrub M. Persuasion as respect for persons. J Med Philos 2001;26:13-24.

4 World Health Organisation, expert committee. Cancer pain relief and palliative care, Geneva: WHO, 1990.

5 Barilan YM. Terminal sedation, terminal elation and medical parsimony. Ethics in Medicine 2004. In press.

6 McCloskey HJ. The right to life. Mind 1975;84:403-25.

7 Barilan YM. Some Jewish aspects of health and quality of life. In: Gimmler A, Lenk C, Aumueller G, eds. Health and quality of life-philosophical, medical, and cultural aspects. Muenster: Lit-Verlag, 2002:157-72.

8 Barilan YM. Revisiting the problem of Jewish bioethics: the case of terminal care. Kennedy Inst Ethics J 2003;13:143-70.

9 Kamm FM. Moral intuitions, cognitive psychology, and the harming-versusnot-aiding distinction. Ethics 1998;108:463-88.

10 Waldenberg E. Tits Eliezer 1985; 13:responsa 89.

11 Zohar N. Alternatives in Jewish bioethics. Albany: SUNY Press: ch 2

12 Rosner F. Euthanasia. In: Dorff EN, Newman LE, eds. Contemporary Jewish bioethics, a reader. New York: Oxford University Press, 1995: ch 25.

13 Sherwin B. A view of euthanasia. In: Dorff EN, Newman LE, eds. Contemporary Jewish bioethics, a reader. New York: Oxford University Press, 1995: ch 26.

14 Dorff EN. Matters of life and death: a Jewish approach to modern medical ethics. Philadelphia: Jewish Publication Society, 1998.

15 Pellegrino ED, Faden Al, eds. Jewish and Catholic bioethics: an ecumenical dialogue. Washington: Georgetown University Press, 1999.

16 Resnicoff SH. Suicide and physician assisted dying. In: Brefer MJ, ed. Jewish public policy in the 21 st century. In press. http://www.jlaw.com/Articles/ phys-suicide.html\#Note2 (accessed 14 Apr 2004).

17 Sternbuch M. Teshuvoth ve'Hanhagoth 1992;1:responsa 859, 561.

18 Dewey J. Logical method and law. Cornell Law Rev 1924;10:17-27.

19 Feenberg A. Questioning technology. New York: Routledge, 1999:1 $1 \mathrm{ff}$.

20 Sandman L. A good death: on the value of death and dying. Gothenburg: Acta Universitatis Gothoburgensis, 2001:274ff.

21 Welie JV. Why physicians? Reflections on the Netherlands' new euthanasia law. Hastings Cent Rep 2002;32:42-4. 